Review

\title{
Evaluating the Application of Rock Breakage without Explosives in Underground Construction-A Critical Review of Chemical Demolition Agents
}

\author{
Kelly-Meriam Habib, Shahé Shnorhokian * and Hani Mitri (D)
}

check for

updates

Citation: Habib, K.-M.;

Shnorhokian, S.; Mitri, H. Evaluating the Application of Rock Breakage without Explosives in Underground Construction-A Critical Review of Chemical Demolition Agents. Minerals 2022, 12, 220. https:// doi.org/10.3390/min12020220

Academic Editors: Anye Cao and Zhenlei Li

Received: 29 December 2021

Accepted: 4 February 2022

Published: 9 February 2022

Publisher's Note: MDPI stays neutral with regard to jurisdictional claims in published maps and institutional affiliations.

Copyright: (C) 2022 by the authors. Licensee MDPI, Basel, Switzerland. This article is an open access article distributed under the terms and conditions of the Creative Commons Attribution (CC BY) license (https:// creativecommons.org/licenses/by/ $4.0 /)$.
Department of Mining and Materials Engineering, McGill University, Montreal, QC H3A 0E8, Canada; kelly-meriam.habib@mail.mcgill.ca (K.-M.H.); hani.mitri@mcgill.ca (H.M.)

* Correspondence: shahe.shnorhokian@mcgill.ca; Tel.: +1-514-432-2222

\begin{abstract}
The method of drilling and blasting with explosives is widely used in rock fragmentation applications in underground construction projects, such as tunnels and caverns. However, the use of explosives is associated with rigorous safety and environmental constraints, since blasting creates toxic fumes, ground vibrations, and dust. Because of these constraints, there has been a growing interest in transitioning away from explosives-based rock fragmentation. The use of explosives-free methods could lead to continuous operation by eliminating the need for idle time with additional ventilation required to exhaust the blast fumes. This paper first presents a critical review of various methods that have been developed so far for rock fragmentation without explosives. Such methods include thermal fragmentation, plasma blasting, controlled foam injection, radial-axial splitter, and supercritical carbon dioxide. Thermal fragmentation, as the name implies, uses high heat to spall high-grade ore. However, it requires high heat energy, which requires additional ventilation as compared to normal conditions to cool the work area. Plasma blasting uses a high temperature and pressure plasma to fracture rock in a safe manner. While this method may be environmentally friendly, its usage may significantly slow tunnel development due to the need to haul one or more large energy capacitor banks into and out of the work area repeatedly. Controlled foam injection is another chemical method, whereby foam is the medium for fracturing. Although claimed to be environmentally friendly, it may still pose safety risks such as air blast or flyrock due to its dynamic nature. A radial-axial splitter (RASP) is an instrument specially designed to fracture a borehole in the rock face but only at the pace of one hole at a time. Supercritical carbon dioxide is used with the equipment designed to provide a high-pressure jet stream to fracture rock, and replaces water in these instruments. The method of soundless chemical demolition agents (SCDA) is evaluated in more detail and its merits over others are highlighted, making it a potentially viable alternative to blasting with explosives in underground excavation applications. Future work involves the optimization of SCDA for implementation in underground mines. The discussion compares the key features and limitations, and future work needs are underlined.
\end{abstract}

Keywords: rock fragmentation; explosive-free rock breakage; tunneling; mining; plasma blasting; thermal fragmentation; controlled foam injection; radial axial splitter; supercritical carbon dioxide; soundless chemical demolition agents

\section{Introduction}

Rock excavation methods can be classified into three categories: drill and blast (DB), mechanical excavation, and specialized explosive-free approaches. The primary method for rock fragmentation in hard rock underground mines, tunnels, and caverns has typically included the use of explosives [1]. An explosive or a blasting agent is defined as a compound, or a mixture of compounds, that, when initiated by heat, can undergo rapid decomposition and release large amounts of heat and gas. The resulting end-products are 
gases that are under compression, elevated temperatures, and very high pressures from ambient conditions, which results in a shockwave traveling through the surrounding rock mass. An ideal detonation is an oxygen-balanced mixture in which there is no excess or deficiency in oxygen so that the gaseous products produced are mainly $\mathrm{H}_{2} \mathrm{O}$ (water vapor), $\mathrm{CO}_{2}$ (carbon dioxide), and $\mathrm{N}_{2}$ (nitrogen). In actual blasting practices, small amounts of noxious gases, such as $\mathrm{NO}$ (nitric oxide), $\mathrm{NH}_{4}$ (ammonia), $\mathrm{CH}_{4}$ (methane), and solid carbon, are formed, resulting in non-ideal detonations resulting from either a deficiency or excess of oxygen [2]. Apart from the release of these fumes into the open air, the risk also lies in these fumes remaining in the ground after the blast. They have the potential to migrate hundreds of meters through the ground, to collect in confined spaces and be released later during subsequent blast loading operations, thus posing serious health risks [3]. Additionally, blasting can lead to poor fragmentation due to adverse joint orientation, resulting in oversized boulders or fine particles and low muck piles. Due to the concentrated energy of explosives, a blast can cause bedding plane separation or new fractures in the host rock; this is known as blast damage [4].

At the heart of the excavation process, there are several basic and fundamental tasks whose regular and repeated performance constitute the drill-and-blast (DB) cycle. Figure 1 presents such a cycle for the application of drift and tunnel advance, the primary method for development in underground mines and other engineering projects at depth. As can be seen, the cycle consists of six activities (1-3 during the first shift and 4-6 during the second one), with the third step being a period for blasting and ventilation of the area to vent out the toxic fumes produced. This period typically lasts for $2 \mathrm{~h}$ in Canadian mines and it usually occurs at the end of a work shift. Thus, for an operation that is running two 10 -h shifts per day, it is possible to carry out blasting during four hours per day. Therefore, the inefficiencies associated with the drill-and-blast method comprise the need to vacate the work area (often the entire mine when several blasts are planned) before detonation. Ventilation then helps the gases generated to be evacuated and dilutes the toxic fumes released to the environment. The process for tunnel face advance in hard rock formations is similar to that of mine drift development.

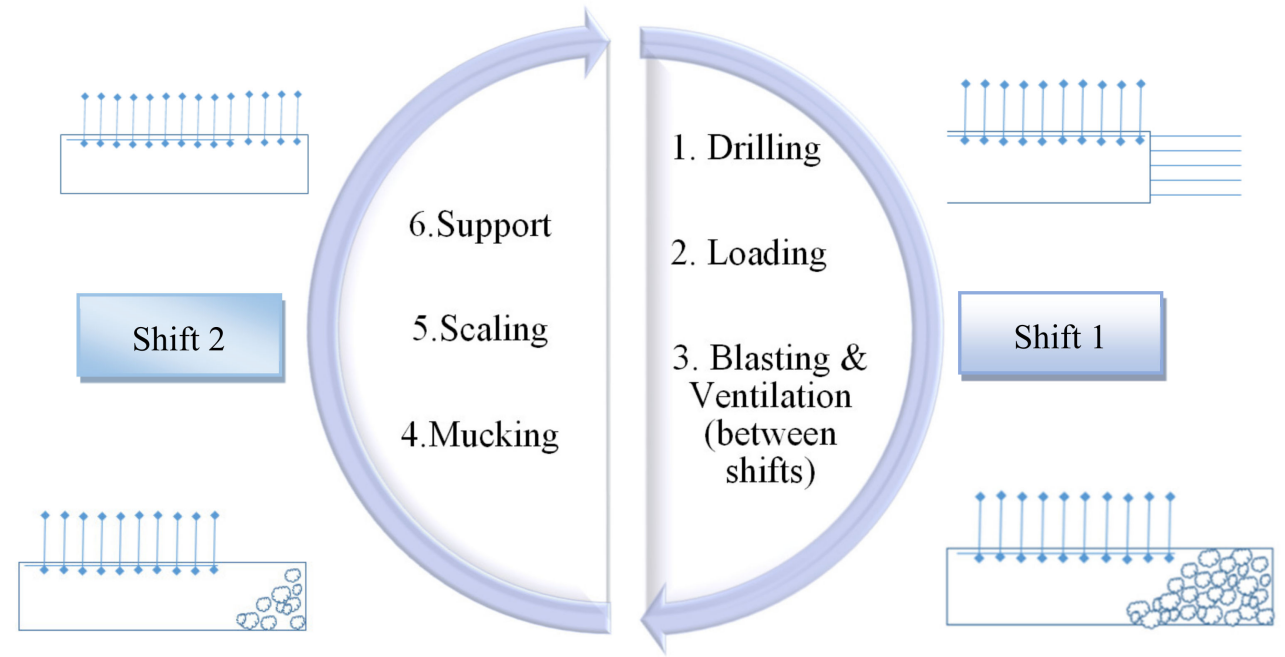

Figure 1. Typical tunnel development cycle with drilling and blasting during two shifts per day.

While drill-and-blast is the most conventional method for rock fragmentation in mine development and ore production, mechanical excavation is also commonly used, especially in soft rock formations. This category comprises the use of a tunnel boring machine (TBM), which can be adopted for tunnel driving in hard rock. Depending on the geology of the site to be excavated, the appropriate type of TBM is selected, such as Hard Rock TBM, Soft Ground, Slurry Shield TBM, Earth Pressure Balance TBM, and Open Face TBM [5]. TBMs have four basic systems to deem them operational: boring, thrust and clamp, muck 
removal, and support. Firstly, the boring system is responsible for cutting through the rock, which involves a cutterhead mounted with disc cutters. The force causes them to rotate and press against the rock face, exerting a higher pressure than the compressive strength of the rock. Secondly, the thrust and clamping system is responsible for moving the TBM via hydraulic cylinders. Thirdly, the muck removal system operates by removing the rock fragments or soil mixed with water or other substances. These are transported by a screw conveyor through the TBM. Lastly, ground support is installed to prevent loose material from falling as the TBM grinds along the tunnel [6].

As explained above, the use of TBMs offers continuous mining since loading and muck removal is done by a single machine as opposed to $\mathrm{DB}$, which involves different equipment to advance a face. TBMs can achieve a daily advance over $20 \mathrm{~m}$ per day, which is much higher than the DB method, being 4-6 m per day. When compared to DB, it is observed that TBMs do not generate blast gases; however, they do generate dust. Additionally, TBMs are high-cost machines and can sometimes be too large for a given site. Therefore, they may not always be suitable for general use in mine development applications [7]. Lastly, TBMs may be limited to applications where the compressive strength of the rock is relatively low. In this regard, various methods of rock preconditioning have been developed over the past few decades to assist with TBMs and other mechanical excavators to drill through hard rock formations and increase their penetration rate. Of these methods, microwave heating has been the most well-known approach.

Microwave heating has been used in the minerals industry to reduce energy requirements for comminution of ores and liberation of valuable particles [8,9]. In rock breakage and excavation applications, it is based on the principle of differential thermal expansion and induced stresses, similar to the fire setting technique used in the Bronze Age [10]. Lindroth et al. applied the technique of microwave heating to two igneous rock types and demonstrated an increase in penetration rate and a decrease in bit wear [11]. Hassani et al. discussed the use of microwave heating to precondition basalt, norite, and granite rock in lab and field demonstrations, as well as modeling the temperature effects [12]. Nekoovaght conducted an extensive investigation into the potential use of microwave-assisted mechanical drilling in rocks for applications with tunnel boring machines (TBMs), especially in relation to reducing bit wear and replacement [13].

It should be underlined that microwave heating can only assist in rock breakage and excavation using mechanical methods and cannot be used on its own for these activities. Research is ongoing to develop a methodology to assess whether a certain type of rock would benefit from microwave heating to render it more breakable. For example, Lu et al. developed a specialized apparatus that produced fractures in underground hard rock to help with their excavation and to reduce rock burst potential [14]. Xu et al. used microwaves to fracture diabase rock samples and modeled the thermal distribution in them [15]. Zheng et al. examined 15 rock types that were treated by microwaves in terms of their susceptibility to breakage, underlining the importance of effective dielectric loss factor and average grain size [16].

While drill-and-blast and mechanical methods are the two main categories for rock excavation techniques, an increasing amount of interest has been drawn in recent years towards the use of explosives-free specialized methods. The development of such methods offers the advantage of eliminating the disruption to tunneling activities-step 3 in Figure 1 -and avoids blast fumes, dust, and noise, while potentially reducing damage to wall rock and achieving a better fragment size distribution. In the following sections, a review of recent methods for rock breakage without explosives is presented, briefly explaining the fundamental concepts behind each method, and highlighting its limitations and features. 


\section{Explosive-Free Specialized Methods}

\subsection{Thermal Fragmentation}

Thermal fragmentation is a method patented in 2005 by Nippon Dragon Resources Inc., (Chicoutimi, QC, Canada) a Canadian junior mining company [4]. The "thermal fragmentation" process is developed for a specific mining application involving the extraction of high-grade, base metal, narrow-vein deposits, which impose a great challenge with respect to high levels of ore dilution. This occurs when a large and unaccounted quantity of waste rock must be processed to retrieve a small quantity of desired material. As shown in Figure $2 a$, the thermal fragmentation method involves using a specialized machine named the Nippon Dragon that can move, drill, and mine ore from a sill drive.

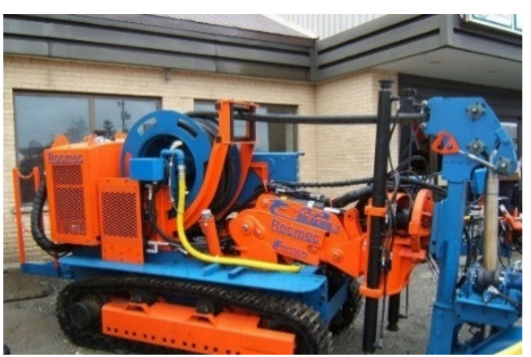

(a)

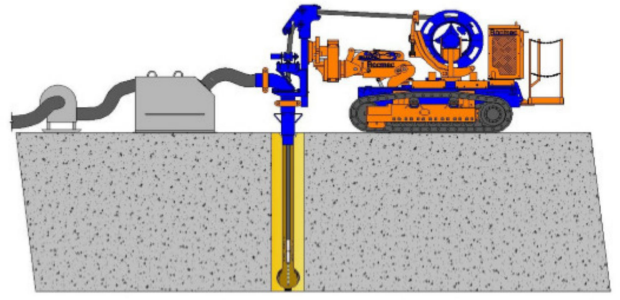

(b)

Figure 2. Thermal fragmentation machinery, (a) Nippon Dragon Machine; (b) Mounted drill of the thermal fragmentation method (reprinted from [17]).

Compared to the conventional blasting method, pilot holes are directly drilled into the desired vein below. The hole dimensions are typically $152.4 \mathrm{~mm}$ (6 inch) in diameter, and the stope height is $12-18 \mathrm{~m}$. The pilot holes are subsequently enlarged by thermal fragmentation, which involves the insertion of a strong burner powered by diesel fuel and air and ignited. In underground mines, the burner can be a plasma torch where temperatures up to $1800^{\circ} \mathrm{C}$ can be generated, thus creating thermal stresses that expand the pilot hole and cause the rock to spall. The hard rock breaks into a range of fragments ranging in size from fine grains to $40.64 \mathrm{~mm}$ (1.6 inch) pieces. Once the area of interest is fragmented, the burner is retracted and the process is repeated until the top of the hole is reached. The fragmented pieces are then removed by a vacuum device. With that, the ore from the narrow vein deposit can be extracted while avoiding the undesired stripping of the surrounding waste rock that causes high dilution. The thermal fragmentation method is commonly used in underground and open pit mines, mineral exploration, and tunneling in many countries, such as Canada, European countries, and Japan [4].

While thermal fragmentation may be beneficial in reducing ore dilution and, hence, the operational cost of narrow vein mining (ore deposits that are less than 2-m wide), there are other factors to consider. The thermal fragmentation method generates excessive amounts of heat, thus requiring far more ventilation energy to cool the working area than under normal conditions. The method also requires the use of specialized equipment that would necessitate increased capital expenditure and specialized training for the workforce. Finally, thermal fragmentation relies heavily on the presence of ore minerals in the rock matrix - it would be inefficient in gangue or waste rock material. Therefore, it is not a suitable method for mine development activities, such as tunnels, drifts, and crosscuts, which are usually driven in waste rock.

\subsection{Plasma Blasting Technology}

The plasma blasting technology (PBT) developed by Noranda Minerals Inc. uses electrical energy as an excavation method to break hard rock in quarries and for fragmentation purposes in mines. The plasma method is based on the electrohydraulic principle and uses hydraulic energy to generate a shockwave through a liquid medium. These pulses propagate into the rock and lead to fracturing of the surrounding material. As shown in 
Figure 3, the method involves delivering electrical energy across a gap between two holes of coaxial electrode assembly in an electrolyte within a confined area of substance to be blasted. The electrolyte is subjected to a dielectric breakdown in the confined area, resulting in the formation of plasma, which is an ionized gaseous substance that is highly conductive electrically when subjected to high temperatures. The solution subjected to dielectric breakdown for plasma formation can either be water or preferably copper sulphate [18].

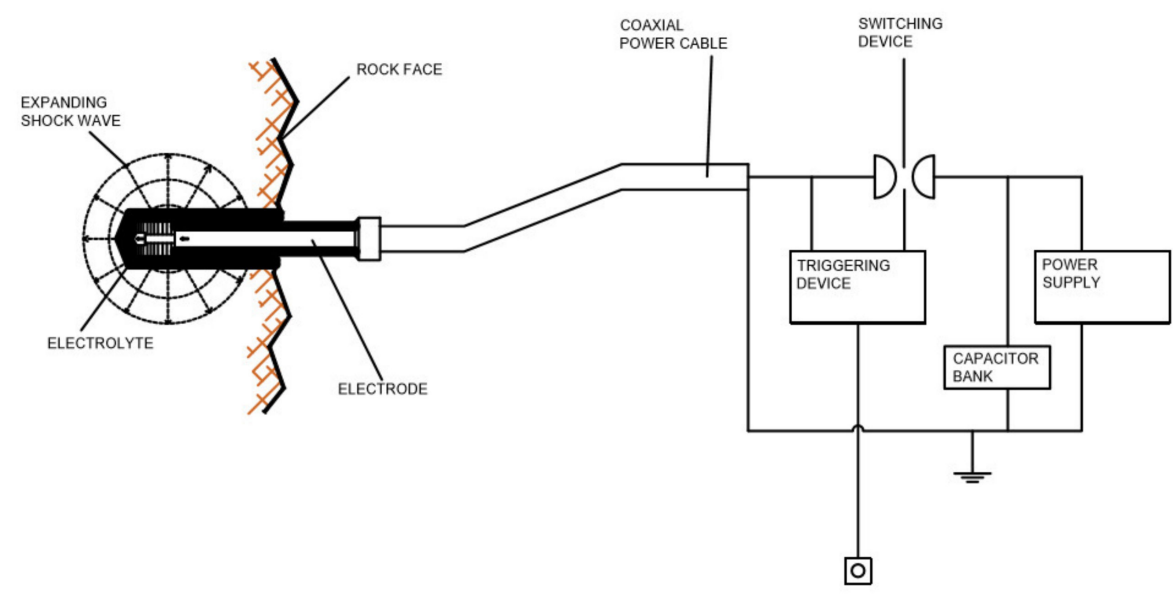

Figure 3. Components of the plasma blasting method (reprinted from [18]).

A gelling agent such as bentonite or gelatin is often added to increase the viscosity of the solution, so that it does not run out of the confined area prior to blasting. The first step requires the drilling of a hole into the rock face by conventional methods, whereby a small amount of viscous electrolyte (20-50 g), such as copper sulphate, is injected into it. As shown in Figure 3, a coaxial blasting electrode is inserted into the hole to supply electrical energy to the electrolyte in the range of 300 to $1000 \mathrm{~kJ}$. A typical size of the drill hole is $50 \mathrm{~mm}$ (1.96 inch) in diameter and $500 \mathrm{~mm}$ (19.69 inch) in depth. The peak pressure developed has been found to be in excess of $1 \mathrm{GPa}$, which is equivalent to blasting hard rock with a high explosive charge [18]. Other work conducted by Ikkurthi et al. on the simulation of crack propagation using two-dimensional numerical modeling showed that increasing the hole pressure beyond a certain threshold would have little incremental benefit to crack formation and propagation. The authors reported that this would be counterproductive, as it could damage the probe [19]. The electrical energy required for the blast is drawn from a capacitor bank which is charged by a DC power source. Once the switch is triggered, the electrolyte in the hole undergoes a dielectric breakdown, producing plasma at extremely high temperature and pressure [18]. The energy created in the confined electrolyte around the electrode is released by way of pressure, which propagates in the rock mass and leads to fracturing. The plasma blasting technology has been tested on cubic concrete blocks $(1200 \mathrm{~kg})$ with successful fragmentation using electrical energies of 60-100 kJ. Another series of tests were conducted successfully on hard rock blocks, such as wollastonite, limey quartzite, and skarn (uniaxial compressive strengths of 140 to $350 \mathrm{MPa}$ ) with electrical energies of 30-180 kJ [20].

While the plasma blasting method is relatively safe and environmentally friendly, its use in underground applications may be limited. For a typical mine drift or tunnel face of $4.5 \mathrm{~m} \times 4.5 \mathrm{~m}$ requiring many drill holes, the electrical energy supply for a single face advance would be very large considering that the plasma pulses would have to be triggered sequentially within a short time delay. Moreover, the need to haul one or more large-sized energy capacitor banks into and out of the work area repeatedly would significantly slow the drift or tunnel development cycle. 


\subsection{Controlled Foam Injection}

The controlled foam injection (CFI) method was developed through extensive research funded by government, mining companies, and original equipment manufacturer (OEM) companies. The CFI method is a controlled process that works by means of pressurizing a fracture (or system of fractures) and maintaining it to propagate them further. The method is based on using high-pressure foam, which consists of a two-phase mixture of a liquid and gas as the fracturing medium. The use of water alone is not enough because its incompressible behavior would cause a rapid loss of pressure as the fracture volume increases. The addition of a gaseous phase provides the necessary expansion to maintain the pressure for efficient fracturing.

To compensate for the separation of the water and air components due to the surface tension properties of water, commercially available surfactants are used to slow down the process. A slower penetration is preferable so that the pressures required to initiate and extend can develop the desired fractures. To obtain a desired viscosity, surfactants such as polyvinyl alcohol and a gel may be used. The process of CFI works by means of delivering the foam to the bottom of a predrilled hole and breaking the rock in tension. Typical operating pressures of the foam are less than $50 \mathrm{MPa}$ and once the device reservoir is filled to the desired level, the foam is released into the predrilled hole by means of a rapid acting reverse firing poppet valve (RAP) (Figure 4) [21]. The typical diameter range is from less than one to several inches, and the hole depth varies from 4- to more than 10-hole diameters [22]. The equipment is mounted on a conventional wheel carrier that supports both the drill and the RAP [21].

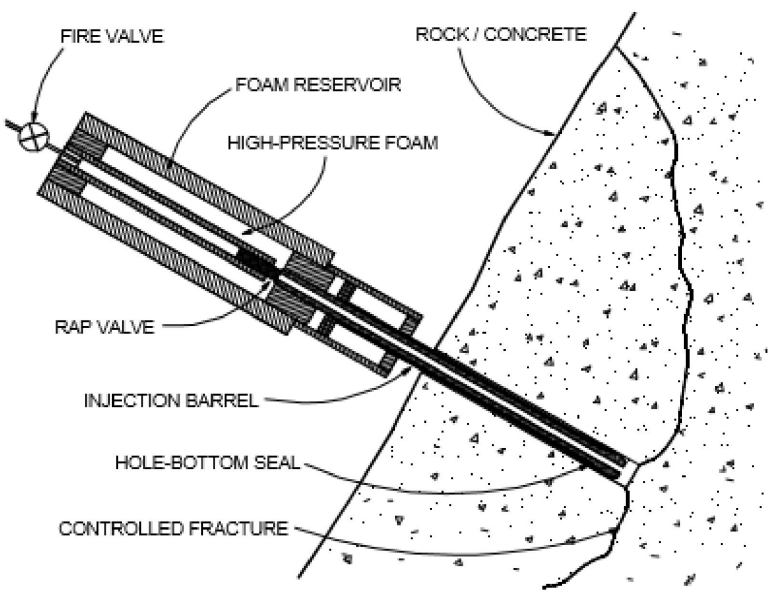

Figure 4. Controlled foam injection components (reprinted from [21]).

Records show that foam at $55 \mathrm{MPa}$ (8000 psi) pressure prior to opening the valve rapidly drops to $48 \mathrm{MPa}$ as the hole is loaded. Series of tests have demonstrated that foam pressures of $48 \mathrm{MPa}$ were not able to immediately fracture granitic rock; however, it was fractured with a small delay of $7.4 \mathrm{~s}$. Once initiated, fracturing was completed in a fraction of a second with about $0.5 \mathrm{t}$ of broken rock. The foam pressure then drops to zero, while the air-cushion pressure drops to $45 \mathrm{MPa}$. Field tests were also conducted at the Colorado School of Mines test mine where CFI has been installed on several drilling machines to demonstrate its functionality. Presently, this method is used to enlarge tunnels but has not been attempted in underground mines [21].

The CFI is claimed to be a more environmentally friendly method due to a significant reduction in dust since exposed rock at the primary fracture is covered in a smear of foam. In addition, none of the surfactants is considered toxic. However, the CFI fracturing process seems to be of a dynamic nature and may still result in air blast or fly rock. There is also a limited depth of penetration, thus presumably preventing continuous excavation at the face. 


\subsection{Radial-Axial Splitter}

A rock splitter is a mechanical tool designed to break or excavate rock or concrete by generating radial and/or radial-axial forces in a pre-drilled hole. The use of radial splitters dates to the beginning of the century and they are currently commercially available for construction and civil engineering applications but have not yet been implemented in hard rock mines. The radial splitter is based on the penetrating cone fracture concept, where a fracture is initiated and propagated by pressurizing a shallow hole through the generation of radial forces. It is initiated at the bottom of the pre-drilled shallow hole and then extends towards the free surface. The extension of the fracture results in the removal of a large volume of rock in the shape of a cone or a bowl, hence the name PCF, which refers to the residual shape left in the rock mass once the block has been broken and removed. This method involves the drilling of a borehole into the material where the radial splitter is inserted; during the penetration of the cone, the rock fails in tension [23]. A typical diameter is $63.5 \mathrm{~mm}$ ( $2.5 \mathrm{inch})$ with a hole depth of $381 \mathrm{~mm}$ (15 inch). For a rock splitter to be rendered effective, a free space must be available and in underground excavations from where a hole is drilled and the splitter inserted [24,25]. Radial-axial splitters (RASP) were introduced and designed by the Swedish Research Institute CERAC, and as the name implies, RASPs generate both radial and axial loads. Figure 5 shows the RASP consisting of the following in-hole components: wedge, thrust, rod, and feather, which are activated by a hydraulic cylinder $[24,25]$. The in-hole components shown in Figure 5 are the mechanical means in which the splitter generates rock breakage. The hydraulic cylinder containing two pistons individually activates the wedge and thrust-rod portion once inserted in a pre-drilled hole. The wedge is drawn back into the feathers, forcing these outwards against the borehole wall, which secures the radial anchorage of the splitter within. The thrust is then extended downwards until contact is made with the bottom and an axial load is applied to the rod. The resulting strain caused by both radial and axial loads, thus, fractures the rock.

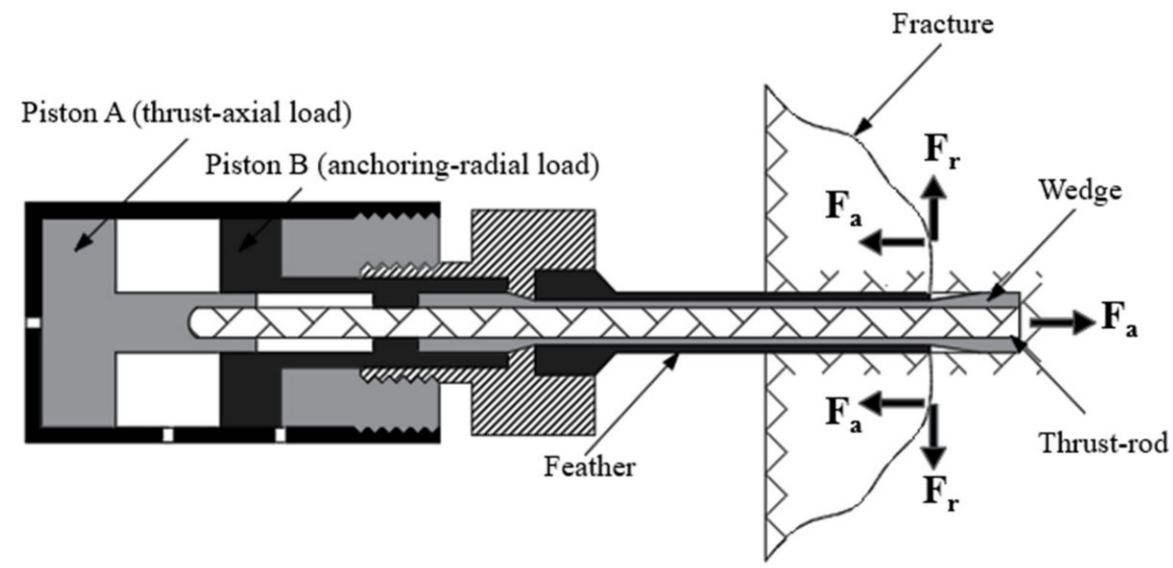

Figure 5. Radial-axial splitter (adapted from [25]).

Large-scale testing was performed in an underground limestone mine near Davenport (IA), owned by Linwood Mining and Minerals Corp, where the operation used the roomand-pillar method. During the field tests, the average depth of break was $254 \mathrm{~mm}$ (10 inch), with 1.25 tons of removed rock per break. The average size of broken rock fell into the range of 20 to $300 \mathrm{lbs}$ [24]. Other studies by Paraszczak and Planeta have conducted feasibility evaluations on the potential use of radial-axial splitters in mining thin and narrow vein deposits for a more controlled fragmentation and to minimize dilution [25].

While this may be considered a safe method for the excavation or removal of hard rock, a significant number of splitters would have to be used for a large mining or tunnel face. They would also have a limited depth of penetration, thus rendering the method a non-continuous one. One of the limitations of radial-axial splitters is that a considerable 
amount of thrust is needed for rock breakage, meaning that the need for the RASP to remain in place can present a challenge for the operator.

\subsection{Supercritical Carbon Dioxide}

The use of supercritical carbon dioxide $\left(\mathrm{SC}-\mathrm{CO}_{2}\right)$ as a drilling fluid was developed at the turn of the 21st century for hydrocarbon reservoir applications [26]. The term "supercritical" indicates the temperature and pressure conditions above which the distinction of a liquid and gaseous phase for a given compound can no longer be made. Hence, the mixture is treated as a fluid since it is no longer in equilibrium. The limit above which $\mathrm{CO}_{2}$ exists as a supercritical fluid is a temperature of $31.1^{\circ} \mathrm{C}$ and a pressure of $7.38 \mathrm{MPa}$.

Caldwell reviewed three commercially available non-explosive technologies for excavation in rock [27]. One of these was Cardox, which was based on liquid carbon dioxide that would be converted to high pressure gas upon ignition, and that broke rocks in tension when it penetrated into the pre-existing fractures. It had been developed in the mid-20th century in the UK and could generate pressures of up to $300 \mathrm{MPa}$. In her study, Caldwell reviewed the use of Cardox for excavating a short shaft and tunnel for a sewerage system in Australia [27]. Gupta examined the feasibility of using the $\mathrm{SC}-\mathrm{CO}_{2}$ technology as a drilling fluid at a depleted gas well in Mississippi [28].

Kolle pioneered the use of SC- $\mathrm{CO}_{2}$ with jet-assisted drilling to cut shale, marble, and granite at much lower pressures than with water [29]. A similar comparison of high-pressure jets of water and $\mathrm{CO}_{2}$ was conducted by Du et al. who found that the latter was a much more efficient system than the former [30]. The use of $\mathrm{SC}-\mathrm{CO}_{2}$ in shale gas exploitation was examined by Wang et al. [31]. Liu et al. compared techniques relying on liquid $\mathrm{CO}_{2}$ and $\mathrm{SC}-\mathrm{CO}_{2}$ for hydraulic fracturing applications and concluded that transitioning from the former to the latter would take place in the future [32]. Wang et al. experimented with breaking artificial and natural core samples with $\mathrm{SC}-\mathrm{CO}_{2}$ [33]. On the other hand, Li et al. developed a new cartridge system based on the Cardox concept and tested it at a construction site at the Hunan University Metro Station [34].

\section{Soundless Chemical Demolition Agents (SCDAs)}

The technology of SCDAs was developed more than 30 years ago but only came into commercial use some 10-15 years later for the fracturing of rock and concrete foundations. SCDAs, also known as expansive cements and non-explosive expansive materials (NEEM), are chemical powdery substances with lime ( $\mathrm{CaO}$ or calcium oxide) as the primary ingredient, which expand during curing when under confinement. The crystallization process of lime during the hydration reactions results in a high expansive pressure. Notably, this method of fragmentation works by means of injecting the SCDA mixture into a borehole drilled into a concrete or rock foundation. The resulting crystallization pressure generated by the production of calcium hydroxide crystals creates an effective fracture network around the borehole. Within a confined hole, the SCDA develops compressive normal stresses against its walls. This exerts pressure on the hole circumference in the radial direction and creates tensile stress in the tangential direction. As shown in Figure 6, a fracture is created in the radial direction at the weakest section in the circumference of the borehole. The initial production of the crack will only propagate when the generated stress exceeds the tensile strength of the rock. Therefore, the tensile stress generated by SCDA expansion produces the fracture mechanism responsible for concrete or rock breakage [35]. Based on linear elasticity theory, the stress generated by the SCDA at the hole edge is further reduced in proportion to the square of the distance from the edge of the hole boundary. Therefore, sufficiently high pressures are required to achieve longer fractures.

Presently, SCDAs are commercially available; some of the products on the market include names such as Bristar and Dexpan. These are used in rehabilitation projects in urban areas where blasting with explosives is either prohibited or restricted. Applications include demolition of reinforced concrete and rock block splitting in dimension stone quarries. 


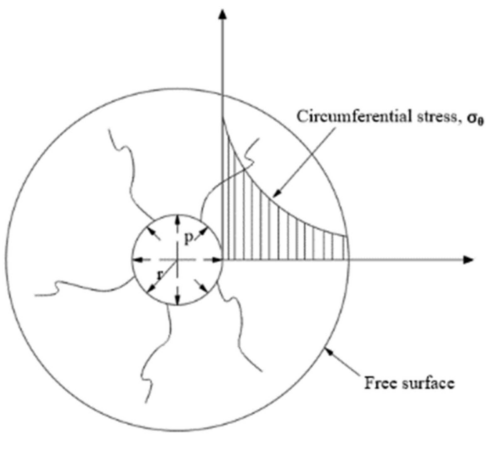

(a)

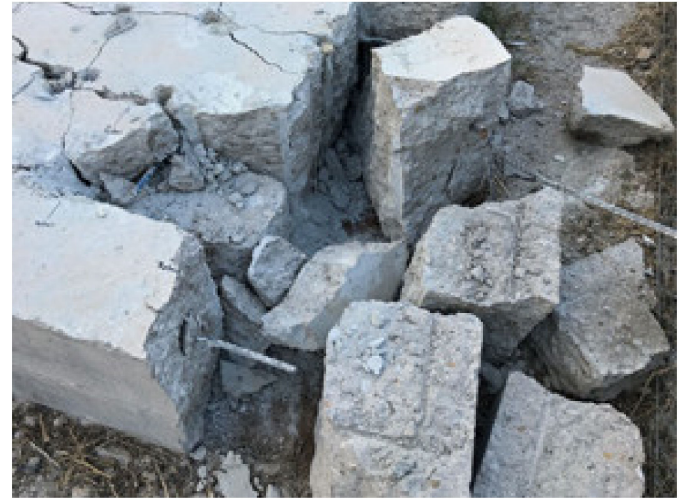

(b)

Figure 6. Soundless chemical demolition agents. (a) Fracture propagation around a pressurized borehole (adapted from [35]). (b) Broken rock with the use of SCDA (reprinted from [36]).

\section{Types of SCDA}

Based on the expansive additive in the product, there are three types of cements that are defined by ASTM C 845 "Standard Specification for Expansive Hydraulic Cement": type K, type M, and type S. Although each one differs in the source of the aluminate component, they all commonly generate ettringite crystals, which is one of the driving forces of its expansive ability [37]. Class $\mathrm{G}$ is another type of expansive cement, and its expansive ability is driven by the generation of Portlandite [38].

Type K

Type $\mathrm{K}$ expansive cement contains anhydrous calcium aluminosulfate $\left(4 \mathrm{CaO} \cdot 3 \mathrm{Al}_{2} \mathrm{O}_{3} \cdot \mathrm{SO}_{3}\right)$, calcium sulphate $\left(\mathrm{CaSO}_{4}\right)$, and uncombined calcium oxide $(\mathrm{CaO})$ [37].

$4 \mathrm{CaO} \cdot 3 \mathrm{Al}_{2} \mathrm{O}_{3} \cdot \mathrm{SO}_{3}+8 \mathrm{CaSO}_{4} \cdot \mathrm{H}_{2} \mathrm{O}+6 \mathrm{Ca}(\mathrm{OH})_{2}+74 \mathrm{H}_{2} \mathrm{O} \rightarrow 3\left(3 \mathrm{CaO} \cdot \mathrm{Al}_{2} \mathrm{O}_{3} \cdot 3 \mathrm{CaSO}_{4} \cdot 32 \mathrm{H}_{2} \mathrm{O}\right)$

Its performance can be enhanced even more by the addition of silica fume and plasticizer as reported by Sarkar [39].

Type M

Type $\mathrm{M}$ expansive cement contains calcium aluminate (CA) and calcium sulphate $\left(\mathrm{CaSO}_{4}\right)[37]$.

$\mathrm{CaO} \cdot \mathrm{Al}_{2} \mathrm{O}_{3}+3 \mathrm{CaSO}_{4} \cdot \mathrm{H}_{2} \mathrm{O}+2 \mathrm{Ca}(\mathrm{OH})_{2}+24 \mathrm{H}_{2} \mathrm{O} \rightarrow 3 \mathrm{CaO} \cdot \mathrm{Al}_{2} \mathrm{O}_{3} \cdot 3 \mathrm{CaSO}_{4} \cdot 32 \mathrm{H}_{2} \mathrm{O}$

Type $S$

Type $\mathrm{S}$ expansive cement is composed of tricalcium aluminate $\left(\mathrm{C}_{3} \mathrm{~A}\right)$ and calcium sulphate $\left(\mathrm{CaSO}_{4}\right)$ [37].

$$
3 \mathrm{CaO} \cdot \mathrm{Al}_{2} \mathrm{O}_{3}+3 \mathrm{CaSO}_{4} \cdot \mathrm{H}_{2} \mathrm{O}+26 \mathrm{H}_{2} \mathrm{O} \rightarrow 3 \mathrm{CaO} \cdot \mathrm{Al}_{2} \mathrm{O}_{3} \cdot 3 \mathrm{CaSO}_{4} \cdot 32 \mathrm{H}_{2} \mathrm{O}
$$

Class G

Class G expansive cement is composed mainly of lime-usually at 80-90\%-and $\mathrm{SiO}_{2}$, as well as a few additional substances, such as $\mathrm{Al}_{2} \mathrm{O}_{3}$ and $\mathrm{Fe}_{2} \mathrm{O}_{3}$, for controlling the expansion rate. The hydration reaction of lime $(\mathrm{CaO})$ is the source of its expansive force [38].

$$
\mathrm{CaO}+\mathrm{H}_{2} \mathrm{O} \rightarrow \mathrm{Ca}(\mathrm{OH})_{2}+15.2 \mathrm{kcal} / \mathrm{mol}
$$

There are several SCDA products that are commercially available, and they all differ in performance, usage instructions, and borehole dimension specifications. The performances are dependent on the curing temperature, water content, borehole dimensions, and borehole 
design pattern. These affect the expansion rate of SCDAs and have been extensively studied by many researchers to optimize their performance. According to studies conducted by Hinze and Brown, the water content is inversely proportional to the expansive pressure generated in the SCDA inside a confined volume [1]. Presumably, this occurs because a lower water-to-cement ratio results in a large agent particle density and smaller distances between neighboring particles. This means that a lower degree of hydration will bring them into contact with one another. Natanzi et al. Laefer et al. and Natanzi et al. have shown that curing and ambient temperatures are directly proportional to expansive pressure [40-42]. This conclusion is also supported by other studies, suggesting that expansive pressure is generated up to a certain threshold that, when exceeded, a blowout of SCDA could occur [1]. The expansive pressure development rate is also affected by the borehole size, and it increases with its diameter due to the hydration reaction and transformation of $\mathrm{CaO}$ into $\mathrm{Ca}(\mathrm{OH})_{2}$. A large diameter provides more space for free lime to be hydrated within the borehole. Since the hydration reaction is exothermic, the chemical reaction releases heat, thus increasing the temperature, which is itself related to the increase in the rate of hydration and one of the main sources of expansion development [1]. Further studies conducted by Soeda et al., Dessouki and Mitri, de Silva and Ranjith, and Habib have shown that common concrete accelerators, such as calcium sulphate, calcium chloride, and calcium formate, can significantly increase the rate of expansive pressure [43-47]. De Silva et al. conducted an extensive study of mineralogical, morphological, and microstructural changes responsible for expansive pressure development in SCDAs [48]. Similar studies have been conducted by other researchers as well, such as Fu et al. [49].

Investigations have also been conducted on borehole spacing patterns, sizes, and lengths to optimize fracture propagation. Etkin and Azarkovitch examined the impact of borehole diameter and length on the pressure developed within SCDAs, while Xu et al. experimented with large-sized diameters in concrete [50,51]. Cho et al., Hutapea et al., and Kim et al. conducted laboratory and field testing specifically to determine borehole spacing and pattern configurations, while Leroy and Chebou studied borehole spacing through numerical modeling [52-55]. Wu et al. combined SCDAs with notching for applications in coal mines where the weakening of the roof formation was required [56]. Arshadnajad conducted an extensive analytical and large-scale test study of the spacing between holes and compared it to those reported in the literature [57]. Studies conducted by Labuz et al. have shown that holes with gradual increased spacing in between-when compared to holes with uniform spacing-caused the fracture to be initiated much sooner and to propagate at a faster rate from the end where the spacing is smaller [58]. Other studies suggest that the fracturing of rock can be optimized by introducing non-injected SCDA holes of the same size as the injected ones. Boreholes with a diameter of $4.76 \mathrm{~mm}$ and a $6 \times 6,4 \times 4$, and $3 \times 3$ grid with non-injected holes were found to be beneficial. In the same study, a potential possibility was observed of reducing the amount of SCDA used and its incorporation into additional empty boreholes [59].

The effect of specimen loading was investigated by Musunuri and Mitri on norite samples by subjecting cubes with a single injected SCDA hole to a uniaxial compression of $64 \mathrm{MPa}$. Results showed that the expansive agent used resulted in pressure generation for up to one week, causing the norite block to fracture and break into fragments [60].

\section{Challenges Associated with SCDA Application to Underground Construction}

SCDAs have traditionally been used in the demolition of concrete structures, debris, and parts of buildings in urban settings, and an extensive body of literature exists on the topic [35,61-71]. Initial applications of expansive cements in general included replacement of the regular type in concrete where shrinkage compensation was required [72]. An extensive literature review of the use of SCDAs is given by Huynh and Laefer [73]. Their usage for rock breakage, mining, or tunneling applications have been fewer in number, with Dowding and Labuz and a related discussion by Ingraffea and Beech being some of the earliest references on the topic $[74,75]$. The former authors used expansive cements to break 
dolomite in a quarry. Hanif et al. used them to break a block of rock from a granite quarry in Saudi Arabia [76]. Bhardwaj and Sharma reviewed the approach as one of the methods that could be used for granite extraction from quarries in India [77]. Arshadnajad et al. conducted numerical modeling in RS2 to study hole spacing to enhance fracture enhancement and propagation [38,78]. Continuing these studies, Gholinajad and Arshadnajad studied the developed pressure within metal cylinders filled with NEEMs extensively for the purpose of using the findings in numerical modeling and rock breakage purposes [79]. The experiment then moved to actual site tests at a granite quarry in Iran $[57,80]$. Cho et al. also used finite element modeling to examine crack propagation due to SCDA expansion [81]. Tiam et al. reported the use of CRACK.AG - an SCDA from China-at a gneiss quarry in central Cameroon at temperatures varying between $16^{\circ} \mathrm{C}$ and $24^{\circ} \mathrm{C}$. They also used XFEM modeling in ABAQUS to study the influence of two adjacent holes on one another [82]. Expanding cements have also been used for well cementing, as well as stimulating and enhancing fracturing for the oil and gas industry [83-86]. Recently, Xu et al. developed special self-swelling SCDA cartridges to be used in up-tilt boreholes [87].

In terms of direct mining and underground construction applications, Dunn reported on a number of non-explosives techniques to break rocks in South African gold mines, including the use of expansive cements that were successful when used in a burden of $200 \mathrm{~mm}$ in norite [88]. De Silva and Ranjith conducted extensive studies of SCDA use to enhance fracturing in host rocks to improve in situ leaching of low-grade ore deposits [46]. They performed laboratory tests and numerical modeling using PFC3D to examine various fracture patterns in cylindrical specimen of sandstone. Xu et al. and Tang et al. used SCDAs to weaken the strong roof at the Pingdingshan coal mine to prevent rockbursts that usually accompanied extraction if blasting agents are used $[89,90]$. They also conducted an analysis of the borehole angle orientation using FLAC3D numerical modeling. Zhang et al. used SCDAs for directional roof cutting at the Donglin coal mine [91]. Tang et al. and Cui et al. have also used it for fracturing and enhancing the permeability of coal seams to release methane and other gases [92,93]. The first trial in an underground hard rock mine has been reported at a manganese operation in Georgia [94]. The authors developed an SCDA capable of producing $130 \mathrm{MPa}$ of expansive pressure and tested it in 42-mm boreholes in ore with tensile strengths of up to $8.1 \mathrm{MPa}$.

An increased interest has been drawn towards SCDA usage in recent years due to its safe and tremor-free breaking up of rock. For subsurface applications, there is the additional benefit of avoiding the generation of greenhouse gas emissions due to blasting with explosives, most notably nitric oxide $(\mathrm{NO})$, carbon monoxide $(\mathrm{CO})$, ammonia $\left(\mathrm{NH}_{4}\right)$, and methane $\left(\mathrm{CH}_{4}\right)$. However, SCDA applications have never been attempted in underground hard rock mines as part of the regular tunnel, drift, and crosscut excavation cycles. There are three main challenges associated with the implementation of the technology in subsurface engineering. Firstly, the time needed for SCDA to develop maximum expansive pressuretypically $12 \mathrm{~h}$-is too long for practical underground applications. Secondly, for SCDA to be rendered feasible, it must overcome the high confining stresses while still achieving a reasonable time for rock breakage. The presence of in situ stresses would require a higher SCDA pressure to overcome not only the tensile strength of the rock, but also the induced compressive stress distribution around the SCDA borehole. The third challenge is that SCDAs have only been tried on concrete and surface rocks formations, which are inherently weaker than the strong igneous lithologies that are commonly found at depth in metal mines and deep underground environments. A sound research methodology is required to overcome the above challenges to help introduce SCDAs into underground construction as a viable alternative for hard rock fragmentation.

If the challenges previously discussed are properly addressed, it would permit the application of a new cycle for drift and tunnel development with SCDAs. Figure 7 presents a proposed continuous, drill-and-fill with an SCDA cycle, with a comparison to the traditional one, shown previously in Figure 1. Firstly, the proposed SCDA cycle (Figure 7) aims at a continuous production schedule, e.g., $3 \times 8$-h or $2 \times 12$-h shifts with no interruption 
in between. The hole diameter of SCDA can range between $25.4 \mathrm{~mm}$ (1.0 inch) and $44.45 \mathrm{~mm}$ (1.75 inch) with a hole depth of at least five times the diameter and maximum $3 \mathrm{~m}$ long [36]. The fact that there is no blasting with explosives would allow for the operation to be continuous, as is the case in mechanical excavation such as roadheaders and TBMs. Productivity would then increase from the traditional $20 \mathrm{~h}(2 \times 10$-h shifts $)$ to $24 \mathrm{~h}$. The change of schedule is also feasible for mines in the period of pre-production development, during which levels and sublevels in waste rock are driven before the beginning of ore extraction with drilling and blasting. The introduction of a mobile rock breaker would be required to help dislodge the fragmented blocks, which is a readily available piece of equipment in most underground construction operations. The use of SCDAs exhibits a quasi-static fracturing process and would presumably not cause damage to the drift sidewall. Thus, the use of SCDAs would have the benefit of eliminating blast-induced vibration and damage, and the need for rock surface scaling would be minimal.

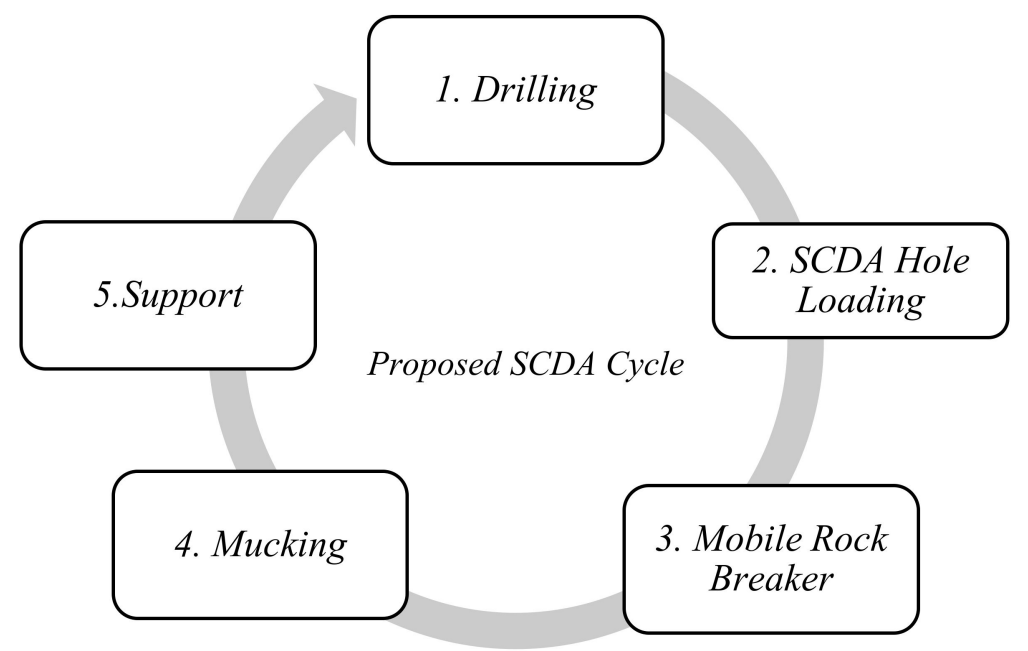

Figure 7. Proposed continuous, drill, and SCDA cycle for tunnel face advance.

While other explosives-free rock breakage technologies demand the introduction of new and specialized equipment (e.g., radial axial splitter) that would further complicate the development schedule and inevitably increase capital and operating costs, SCDA-based technology uses existing standard excavation equipment. This includes the possible use of a mobile rock breaker for the separation of fractured blocks.

Finally, with the use of SCDAs, there will be no blast-induced fumes and fugitive dust particles that get released to the atmosphere and cause air pollution. The SCDA cycle does not necessitate the additional ventilation normally needed to extract blast-induced fumes and dust particles from underground openings. This is an environmentally friendly feature and constitutes a cost reduction factor as well.

Presently, research efforts are underway by the authors at McGill University to overcome the challenges of implementing SCDA-based rock breakage in underground mines, tunnels, and caverns. The main challenges addressed to render this method feasible comprise a reduction in the time of rock breakage and overcoming the confining stress that could prevent fracturing. Of specific interest is the use of SCDA due to its procedural simplicity for operation as well as the minimal training required in handling the material. SCDA is also found to be environmentally safe as it does not generate fumes, noise, and vibrations, thereby mitigating the risks of explosives blasting. Due to these features, SCDAs have the potential to revolutionize rock fragmentation in underground mine, tunnel, and space developments and other hard rock excavation applications. 


\section{Conclusions}

This paper describes six selected explosives-free methods for rock breakage, notably thermal fragmentation, plasma blasting technology, controlled foam injection, radial-axial splitter, supercritical carbon dioxide, and SCDA. Each method offers advantages that mitigate the risks of blasting with explosives while still having their own limitations. Thermal fragmentation is targeted for the extraction of narrow vein deposits to reduce ore dilution; however, its excessive heat requires additional ventilation energy to cool down the work area. While the thermal fragmentation method is presently used in the mining industry, the plasma blasting technology has yet to be implemented and its use may be limited in subsurface applications as a large supply of electrical energy is needed to advance a single face. The controlled foam injection technology is claimed to be environmentally friendly; however, the fracturing method may be of dynamic nature resulting in air blast or fly rock, the safety risks of which explosive-free methods should avoid. The radial-axial splitter, a mechanical method of hard rock excavation, is also considered environmentally friendly; however, a significant number of splitters is needed for the excavation of a single face as well at its limited depth of penetration impeding continuous mining. Supercritical carbon dioxide is a more efficient replacement for water in high-pressure jets used for excavation, but their main function is to simply drill holes into the rock and not fragment a large enough face for mucking. From a practical perspective, it is shown that the proposed SCDA method has the most potential to become a viable alternative to blasting with explosives in underground mine drift advance applications. While SCDA technology is currently being used in demolition projects and dimension stone quarries, it is yet to be developed further for underground tunneling and mining applications. The merits of SCDA can be summarized as follows: (1) Reduced zone of influence around the tunnel excavation, thus having the potential to be implemented in shallow overburden projects near sensitive buildings and infrastructure; (2) Reduced potential for ground water leakage; (3) Noise reduction/elimination; (4) Reduced occurrence of overbreak and strata collapse;

(5) Little or no nuisance to residents in the vicinity of the project.

Author Contributions: Conceptualization, K.-M.H.; methodology, K.-M.H.; software, K.-M.H.; validation, K.-M.H.; formal analysis, K.-M.H.; investigation, K.-M.H.; resources, K.-M.H.; data curation, K.-M.H.; writing—original draft preparation, K.-M.H.; writing—review and editing, S.S. and H.M.; visualization, K.-M.H.; supervision, H.M.; project administration, S.S. and H.M.; funding acquisition, H.M. All authors have read and agreed to the published version of the manuscript.

Funding: This project is financially supported by a research grant from Natural Resources Canada, Clean Growth Program, Grant No. CGP-17-1003 and industry partner Newmont Corporation. The authors are grateful for their support.

Data Availability Statement: The experimental and computational data presented in the present paper is available from the corresponding author upon request.

Conflicts of Interest: The authors declare no conflict of interest.

\section{References}

1. Hinze, J.; Brown, J. Properties of soundless chemical demolition agents. Constr. Eng. Manag. 1994, 120, 816-827. [CrossRef]

2. Dhekne, P.Y. Environmental impacts of rock blasting and their mitigation. Int. J. Chem. Environ. Biol. Sci. $2015,3,46-50$.

3. Özmen, İ.; Aksoy, E. Respiratory Emergencies and Management of Mining Accidents. Turk. Thorac. J. 2015 , 16 (Suppl. S1), S18. [CrossRef]

4. Brisebois, D. Thermal Rock Fragmentation Application in Narrow Vein Extraction. U.S. Patent 7,195,320, 27 March 2007.

5. Encardio Rite. Available online: https://www.encardio.com/blog/all-about-tunnel-boring-machine-components-typesadvantages/ (accessed on 22 January 2022).

6. Maidl, B.; Schmid, L.; Ritz, W.; Herrenknecht, M. Hardrock Tunnel Boring Machines; John Wiley \& Sons: Berlin, Germany, 2008; pp. 15-19.

7. Stewart, P.; Ramezanzadeh, A.; Knights, P. Benchmark drill and blast and mechanical excavation advance rates for underground hard-rock mine development. In Proceedings of the 2006 Australian Mining Technology Conference, Hunter Valley, NSW, Australia, 26-27 September 2006. 
8. Fitzgibbon, K.E.; Veasey, T.J. Thermally assisted liberation-A review. Miner. Eng. 1990, 3, 181-185. [CrossRef]

9. Kingman, S.W.; Vorster, W.; Rowson, N.A. The influence of mineralogy on microwave-assisted grinding. Miner. Eng. 2000, 13, 313-327. [CrossRef]

10. Satish, H. Exploring Microwave-Assisted Rock Breakage for Possible Space Mining Applications. Master's Thesis, McGill University, Montreal, QC, Canada, 2005.

11. Lindroth, D.P.; Berglund, W.R.; Morrell, R.J.; Blair, J.R. Microwave assisted drilling in hard rock. Tunn. Tunn. 1993, 25, 24-27.

12. Hassani, F.; Nekoovaght, P.M.; Gharib, N. The influence of microwave irradiation on rocks for microwave-assisted underground excavation. J. Rock Mech. Geotech. Eng. 2016, 8, 1-15. [CrossRef]

13. Nekoovaght, P.M. Physical and Mechanical Properties of Rock Exposed to Microwave Irradiation: Potential Application to Tunnel Boring. Ph.D. Thesis, McGill University, Montreal, QC, Canada, 2015.

14. Lu, G.M.; Feng, X.T.; Li, Y.H.; Zhang, X. The microwave-induced fracturing of hard rock. Rock Mech. Rock Eng. 2019, 52, 3017-3032. [CrossRef]

15. Xu, T.; He, L.; Zheng, Y.; Zou, X.; Badrkhani, V.; Schillinger, D. Experimental and numerical investigations of microwave-induced damage and fracture formation in rock. J. Therm. Stresses 2020, 44, 513-528. [CrossRef]

16. Zheng, Y.L.; Ma, Z.J.; Yang, S.Q.; Zhao, X.B.; He, L.; Li, J.C. A microwave fracturability index (MFI) of hard igneous rocks. Int. J. Rock Mech. Min. 2021, 138, 104566. [CrossRef]

17. Poirier, S.; Fecteau, J.-M.; Laflamme, M.; Brisebois, D. Thermal rock fragmentation: Applications in narrow-vein extraction. CIM Bull. 2003, 96, 66-71.

18. Kitzinger, F.; Nantel, J. Plasma Blasting Method. U.S. Patent 5,106,164, 21 April 1992.

19. Ikkurthi, V.R.; Tahiliani, K.; Chaturvedi, S. Simulation of crack propagation in rock in plasma blasting technology. Shock Waves 2002, 12, 145-152. [CrossRef]

20. Zhou, H.; Xie, X.; Feng, Y. Rock breaking methods to replace blasting. IOP Conf. Ser. Mater. Sci. Eng. 2018, 322, 022014. [CrossRef]

21. Pickering, R.G.B.; Young, C. Controlled foam injection: A new and innovative non-explosive rockbreaking technology. J. S. Afr Inst. Min. Metall. 2017, 117, 237-243. [CrossRef]

22. Young, C., III. Controlled Foam Injection Method and Means for Fragmentation of Hard Compact and Rock and Concrete. U.S. Patent 6,375,271, 23 April 2002.

23. De Graaf, W.W.; Spiteri, W. A preliminary qualitative evaluation of a hydraulic splitting cylinder for breaking rock in deep-level mining. J. S. Afr. Inst. Min. Metall. 2018, 118, 891-897. [CrossRef]

24. Anderson, S.J.; Swanson, D.E. Capability Evaluation of the Radial-Axial Splitter; Report No. 9071; US Bureau of Mines: Minneapolis, MN, USA, 1987; 35p.

25. Paraszczak, J.; Planeta, S. Feasibility of Narrow Vein Mining Using a Mechanical Rock Splitter. Mine Plan. Equip. Sel. 2003, 1, 415-422.

26. Ishida, T.; Aoyagi, K.; Niwa, T.; Chen, Y.; Murata, S.; Chen, Q.; Nakayama, Y. Acoustic emission monitoring of hydraulic fracturing laboratory experiment with supercritical and liquid CO2. Geophys. Res. Lett. 2012, 39. [CrossRef]

27. Caldwell, T. A comparison of non-explosive rock breaking techniques. In Proceedings of the 12th Australian Tunnelling Conference, Sofitel, Australia, 17-20 April 2005.

28. Gupta, A.P. Feasibility of Supercritical Carbon Dioxide as a Drilling Fluid for Deep Underbalanced Drilling Operations. Master's Thesis, Louisiana State University, Baton Rouge, LA, USA, 2006.

29. Kolle, J.J. Coiled-tubing drilling with supercritical carbon dioxide. In Proceedings of the SPE/CIM International Conference on Horizontal Well Technology, Calgary, AB, Canada, 6-8 November 2000.

30. Du, Y.K.; Wang, R.H.; Ni, H.J.; Li, M.K.; Song, W.Q.; Song, H.F. Determination of rock-breaking performance of high-pressure supercritical carbon dioxide jet. J. Hydrodynam. B 2012, 24, 554-560. [CrossRef]

31. Wang, H.; Li, G.; Shen, Z. A Feasibility Analysis on Shale Gas Exploitation with Supercritical Carbon Dioxide. Energy Sources Part A Recovery Util. Environ. Eff. 2012, 34, 1426-1435. [CrossRef]

32. Liu, H.; Wang, F.; Zhang, J.; Meng, S.; Duan, Y. Fracturing with carbon dioxide: Application status and development trend. Pet. Explor. Dev. 2014, 41, 513-519. [CrossRef]

33. Wang, H.; Li, G.; Shen, Z.; Tian, S.; Sun, B.; He, Z.; Lu, P. Experiment on rock breaking with supercritical carbon dioxide jet. J. Pet. Sci. Eng. 2015, 127, 305-310. [CrossRef]

34. Li, Q.Y.; Chen, G.; Luo, D.Y.; Ma, H.P.; Liu, Y. An experimental study of a novel liquid carbon dioxide rock-breaking technology. Int. J. Rock Mech. Min. 2020, 128, 104244. [CrossRef]

35. Harada, T.; Idemitsu, T.; Watanabe, A.; Takayama, S. The Design Method for the Demolition of Concrete with Expansive Demolition Agents. In Fracture of Concrete and Rock; Shah, S.P., Swartz, S.E., Eds.; Springer: New York, NY, USA, 1989; pp. 47-57.

36. Betonamit Technical Manual-Non-Explosive Cracking Agent. Available online: http://www.betonamit.com/technical-manual/ (accessed on 9 April 2021). 
37. ASTM International. Standard Specification for Expansive Hydraulic Cement. In Annual Book of ASTM Standards; 845 Standard; ASTM International: West Conshohocken, PA, USA, 2004; pp. 390-393.

38. Arshadnejad, S.; Goshtasbi, K.; Aghazadeh, J. A model to determine hole spacing in the rock fracture process by non-explosive expansion material. Int. J. Miner. Metall. 2011, 18, 509-514. [CrossRef]

39. Sarkar, S.L. Strength Enhancement in Type K Expansive Cement Using Additives. J. Mater. Civ. Eng. 1990, 2, 1-14. [CrossRef]

40. Natanzi, A.S.; Laefer, D.F.; Connolly, L. Cold and moderate ambient temperatures 965 effects on expansive pressure development in soundless chemical demolition agents 966. Constr. Build. Mater. 2016, 110, 117-127. [CrossRef]

41. Laefer, D.F.; Natanzi, A.S.; Zolanvari, S.M.I. Impact of thermal transfer on hydration heat of a Soundless Chemical Demolition Agent. Constr. Build. Mater. 2018, 187, 348-359. [CrossRef]

42. Natanzi, A.S.; Laefer, D.F.; Connolly, L. Temperature-Induced Chemical Changes in Soundless Chemical Demolition Agents. J. Mater. Civ. Eng. 2019, 31, 04019098. [CrossRef]

43. Soeda, K.; Hida, T.; Hayashi, H.; Kanbayashi, M. The Influence of Additives on the Expansive Stress of Quick Lime. Gypsum \& Lime. J. Korean Ceram. Soc. 1992, 44, 79-84.

44. Soeda, K.; Matsuhisa, M.; Hayashi, H.; Tsuchiya, K. The Influence of Chemical Composition on the Properties of Non-explosive Demolition Agent for Low Temperatures. Gypsum Lime J-Stage 1993, 247, 442-449.

45. Dessouki, A.E.; Mitri, H. Rock Breakage Using Expansive Cement. Engineering 2011, 3, 168-173. [CrossRef]

46. De Silva, V.R.S.; Ranjith, P.G. Intermittent and multi-stage fracture stimulation to optimize fracture propagation around a single injection well for enhanced in-situ leaching applications. Eng. Fract. Mech. 2019, 220, 106662. [CrossRef]

47. Habib, K. Laboratory Investigation into Soundless Chemical Demolition Agents for Rock Breakage in Underground Mines Master's Thesis, McGill University, Montreal, QC, Canada, 2019.

48. De Silva, V.R.S.; Ranjith, P.G.; Perera, M.S.A.; Wu, B.; Rathnaweera, T.D. Investigation of the mechanical, microstructural and mineralogical morphology of soundless cracking demolition agents during the hydration process. Mater. Charact. 2017, 130, 9-24. [CrossRef]

49. Fu, Y.; Sheikh, S.A.; Hooton, R.D. Microstructure of Highly Expansive Cement Pastes. ACI Mater. J. 1994, 91-M6, 46-53.

50. Etkin, M.B.; Azarkovich, A.E. Effect of Non-Explosive Splitting Compounds and Rational Work Parameters. Power Technol. Eng. 2006, 40, 23-29.

51. Xu, Q.; Jiang, N.; Long, Y.; Liao, Y.; Yang, T.; Ji, R. Investigation of the Large-Scale Borehole Soundless Cracking Experiment on the Concrete Members. Appl. Mech. Mater. 2015, 782, 219-226. [CrossRef]

52. Cho, H.; Nam, Y.; Kim, K.; Lee, J.; Sohn, D. Effective Arrangement of Non-Explosive Demolition Agents and Empty Holes for Improving Fragmentation of Square Concrete Structures. J. Comput. Struct. Eng. Inst. Korea 2017, 30, 145-151. [CrossRef]

53. Hutapea, E.H.; Simangunsong, G.M.; Widodo, N.P. Laboratory Investigation to Determine Hole Spacing into Rock Fracturing Using Non-Explosive Demolition Agent. In Proceedings of the ISRM Specialized Conference, Jeju, Korea, 10 May 2017.

54. Kim, K.; Cho, H.; Sohn, D.; Koo, J.; Lee, J. Prediction of the Minimum Required Pressure of Soundless Chemical Demolition Agents for Plain Concrete Demolition. J. Comput. Struct. Eng. Inst. Korea 2018, 31, 221-258. [CrossRef]

55. Leroy, M.N.L.; Chebou, G.N. Numerical Study of Stresses around Holes Drilled and Filled by Expansive Cement: Case of Isotropic Linear Elastic Block of Rock. Adv. Mater. Sci. Eng. 2018, 2018, 8718452. [CrossRef]

56. Wu, S.; Zhai, C.; Xu, J.; Qin, L.; Sun, Y.; Dong, R. The performance of soundless cracking agents for weakening rock roof under different notch angles. Arab. J. Geosci. 2019, 12, 365. [CrossRef]

57. Arshadnejdad, S. Design of hole pattern in static rock fracture process due to expansion pressure. Int. J. Rock Mech. Min. 2019, 123, 104100. [CrossRef]

58. Labuz, J.F.; Shah, S.P.; Dowding, C.H. Experimental analysis of crack propagation in granite. Int. J. Rock Mech. Min. 1985, 22, 85-98. [CrossRef]

59. Gambatese, J.A. Controlled concrete demolition using expansive cracking agents. J. Constr. Eng. Manag. 2003, 129, 98-104. [CrossRef]

60. Musunuri, A.; Mitri, H. Laboratory investigation into rock fracturing with expansive cement. Int. J. Min. Miner. 2009, 1, 327-345. [CrossRef]

61. Gomez, C.; Mura, T. Stresses Caused by Expansive Cement in Borehole. J. Eng. Mech. 1984, 110, 1001-1005. [CrossRef]

62. Tarricone, P. Less Bang for the Buck. Civ. Eng. 1990, 60, 64-66.

63. Abudayyeh, O.; Sawhney, A.; El-Bibany, H.; Buchanan, D. Concrete Bridge Demolition Methods and Equipment. J. Bridge Eng. 1998, 3, 117-125. [CrossRef]

64. Laefer, D.F.; Ambrozevitch-Cooper, N.; Huynh, M.P.; Midgette, J.; Ceribasi, S.; Wortman, J. Expansive fracture agent behaviour for concrete fracking. Mag. Concr. Res. 2010, 62, 443-452. [CrossRef]

65. Natanzi, A.S.; Laefer, D.F. Using Chemicals as Demolition Agents Near Historic Structures. In Proceedings of the 9th International Conference on Structural Analysis of Historical Constructions, Mexico City, Mexico, 14-17 October 2014.

66. Laefer, D.F. Emerging city-scale damage prediction options for urban tunnelling. In Proceedings of the 10th International Conference on Structural Analysis of Historical Constructions, Leuven, Belgium, 13-15 September 2016. 
67. De Silva, V.R.S.; Ranjith, P.G.; Perera, M.S.A. An Alternative to Conventional Rock Fragmentation Methods Using SCDA: A Review. Energy J. 2016, 9, 958. [CrossRef]

68. Natanzi, A.S.; Laefer, D.F.; Mullane, S. Chemical Demolition of Unit Masonry: A Preparatory Study. In Proceedings of the 10th International Conference on Structural Analysis of Historical Constructions: Anamnesis, Diagnosis, Therapy, Controls, Leuven, Belgium, 13-15 September 2016.

69. Natanzi, A.S. Soundless Chemical Demolition Agents Performance under Cold and Cool Temperatures in Concrete and Masonry Structures. Ph.D. Thesis, University College Dublin, Dublin, Ireland, 2017.

70. Wiggenhauser, H.; Kopp, C.; Timofeev, J.; Azari, H. Controlled Cracks in Concrete for Non-destructive Testing. J. Nondestr. Eval 2018, 37, 67. [CrossRef]

71. Saltas, V.; Peraki, D.; Vallianatos, F. The use of acoustic emissions technique in the monitoring of fracturing in concrete using soundless chemical demolition agent. Frat. Integrita Strutt. 2019, 13, 505-516. [CrossRef]

72. Hoff, G.C. Expansive Cements and Their Use; U.S. Army Engineer Waterways Experiment Station Concrete Laboratory: Vicksburg, MS, USA, 1972.

73. Huynh, M.-P.; Laefer, D.F. Expansive cements and soundless chemical demolition agents: Sate of technology review. In Proceedings of the 11th Conference on Science and Technology, Tsukuba, Japan, 21-23 October 2009.

74. Dowding, C.H.; Labuz, J.F. Fracturing of Rock with Expansive Cement. J. Geotech. Eng. 1982, 108, 1288-1299. [CrossRef]

75. Ingraffea, A.R.; Beech, J.F. Discussion to "Fracturing of Rock with Expansive Cement". J. Geotech. Eng. 1983, 109, 1205-1208. [CrossRef]

76. Hanif, M.; Al-Maghrabi, M.-N.N.H. Effective Use of Expansive Cement for the Deformation and Fracturing of Granite. Gazi Univ. J. Sci. 2007, 20, 1-5.

77. Bhardwaj, G.S.B.; Sharma, S. Granite Extraction and Treatment Techniques: A Study on Cost Effective Geo-Technical Aspects. Min. Eng. J. 2010, 11, 11-19.

78. Arshadnejad, S.; Goshtasbi, K.; Aghazadeh, J. Stress Concentration analysis between two neighboring circular holes under internal pressure of a non-explosive expansion material. J. Earth Sci. Appl. Res. Cent. Hacet. Univ. 2009, 30, $259-270$.

79. Gholinejad, M.; Arshadnejad, S. An experimental approach to determine the hole-pressure under expansion load. J. S. Afr. Inst. Min. Metall. 2012, 112, 631-635.

80. Arshadnejad, S. Analysis of the First Cracks Generating between Two Holes under Incremental Static Loading with an Innovation Method by Numerical Modelling. Math. Comput. Sci. 2017, 2, 120-129. [CrossRef]

81. Cho, H.; Nam, Y.; Kim, K.; Lee, J.; Sohn, D. Numerical Simulations of crack path control using soundless chemical demolition agents and estimation of required pressure for plain concrete demolition. Mater. Struct. 2018, 51, 169. [CrossRef]

82. Tiam, F.F.K.; Danwe, R.; Konai, N.; Meva'a, L. Experimental Study and Numerical Simulation Using Extended Finite Element Method (XFEM) Combined with Cohesive Zone Model (CZM), of Crack Growth Induced by Non-Explosive Expansive Materials on Two Neighboring Circular Holes of A Gneiss Rock. Open J. Appl. Sci. 2020, 10, 592-612. [CrossRef]

83. Parker, P.N.; Wahl, W.W. Expanding Cement-A New Development in Well Cementing. J. Pet. Technol. 1966, 18, 559-564. [CrossRef]

84. De Silva, V.R.S.; Ranjith, P.G.; Perera, M.S.A.; Wu, B.; Rathnaweera, T.D. A modified, hydrophobic soundless cracking demolition agent for non-explosive demolition and fracturing applications. Process Saf. Environ. Prot. 2018, 119, 1-13. [CrossRef]

85. De Silva, V.R.S.; Ranjith, P.G.; Perera, M.S.A.; Wu, B. Artificial Fracture Stimulation of Rock Subjected to Large Isotropic Confining Stresses in Saline Environments: Application in Deep-Sea Gas Hydrate Recovery. Nat. Resour. Res. 2019, $28,563-583$. [CrossRef]

86. De Silva, V.R.S.; Ranjith, P.G.; Perera, M.S.A.; Wu, B. The effect of saturation conditions on fracture performance of different soundless cracking demolition agents (SCDAs) in geological reservoir rock formations. J. Nat. Gas Sci. Eng. 2019, 62, 157-170. [CrossRef]

87. Xu, S.; Hou, P.; Li, R.; Cai, M. An Experimental Study on the Mechanical Properties and Expansion Characteristics of a Novel Self-Swelling Cartridge for Rock Breakage. Rock Mech. Rock Eng. 2020, 54, 819-832. [CrossRef]

88. Dunn, P.G. The Non-Explosive Mechanization of the South African Gold Mine Stoping Operation. Master's Thesis, University of the Witwatersrand, Johannesburg, South Africa, 1989.

89. Xu, J.; Cheng, Z.; Ranjith, P.G.; Sun, Y.; Qin, L.; Ma, H.; Guo, J.; Ma, Z. Investigation of non-explosive expansion material in roof caving field application. Int. J. Rock Mech. Min. 2019, 120, 50-57. [CrossRef]

90. Tang, W.; Zhai, C.; Xu, J.; Sun, Y.; Cong, Y.; Zheng, Y. The influence of borehole arrangements of soundless cracking demolition agents (SCDAs) on weakening the hard rock. Int. J. Min. Sci. Technol. 2021, 31, 197-207. [CrossRef]

91. Zhang, Q.; He, M.; Wang, J.; Guo, S.; Guo, Z.; Liu, X.; Hu, J.; Ma, Z.; Fan, L.; Guo, P. Instantaneous expansion with a single fracture: A new directional rock-breaking technology for roof cutting. Int. J. Rock Mech. Min. 2020, 132, 104399. [CrossRef]

92. Tang, S.B.; Huang, R.Q.; Wang, S.Y.; Bao, C.Y.; Tang, C.A. Study of the fracture process in heterogeneous materials around boreholes filled with expansion cement. Int. J. Solids. Struct. 2017, 112, 1-15. [CrossRef] 
93. Cui, X.; Zhang, J.; Guo, L.; Gong, X. Experimental Investigation of the Use of Expansive Materials to Increase Permeability in Coal Seams through Expansive Fracturing. Shock Vib. 2020, 2020, 7925724. [CrossRef]

94. Akhvlediani, T.; Mataradze, E.; Chikhradze, N.; Gabadadze, T.; Suladze, I. Investigation of New Non-Explosive Demolition Agent for Use at Underground Mining of Hard Ores. Min. Geol. Int. Sci. Conf. 2008, 1, 281. 